\title{
Transgender identity and cryptorchidism: A case study
}

\author{
Tania Real Quintanar,' Rebeca Robles García, ' María Elena Medina-Mora, Juan Carlos Jorge, ${ }^{2}$ Lucía Vázquez Pérez³
}

\begin{abstract}
Centro de Investigación en Salud Mental Global, Dirección de Investigaciones Epidemiológicas y Psicosociales, Instituto Nacional de Psiquiatría Ramón de la Fuente Muñíz, Mexico City, Mexico.

2 Departamento de Anatomía y Neurobiología, Escuela de Medicina, Universidad de Puerto Rico, San Juan, Puerto Rico.

3 Departamento de Investigaciones Epidemiológicas y Psicosociales, Dirección de Investigaciones Epidemiológicas y Psicosociales, Instituto Nacional de Psiquiatría Ramón de la Fuente Muñíz, Mexico City, Mexico.
\end{abstract}

\section{Correspondence}

Rebeca Robles García

Centro de Investigación en Salud Mental Global, Dirección de Investigaciones Epidemiológicas y Psicosociales, Instituto Nacional de Psiquiatría Ramón de la Fuente Muñíz. Calzada México-Xochimilco 101, San Lorenzo Huipulco, Tlalpan, 14370, Ciudad de México, México. Phone: 4160 - 5143

Email: reberobles@imp.edu.mx

Received: 3 November 2018

Accepted: 5 February 2019

\section{Citation:}

Real Quintanar, T., Robles García, R., Medina-Mora, M. E., Jorge, J. C. Vázquez Pérez, L. Transgender identity and cryptorchidism: A case study Salud Mental, 42(1), 51-57.

DOI: 10.17711/SM.0185-3325.2019.007

\begin{abstract}
Introduction. There is a wide range of possible combinations in relation to sex at birth, gender identity, and sexual orientations. Specific medical and psychological treatment needs may also vary depending on these combinations. Objective. In order to promote interventions that focus on the perceived needs of those directly involved, the aim of the present case study is to describe the clinical and life experiences of a 43-year old transgender woman with cryptorchidism and examine the interplay between this relative common testicular problem at birth, gender identity, and sexual orientation formation processes from her own perspective. Method. An in-depth interview was conducted at a specialized care centre in Mexico City, Mexico. The interview was audio recorded and transcribed for a content analysis. Results. The case under analysis was assigned to the male sex and identified herself as a transgender woman and lesbian. Although it is not possible to conclude that her gender identity or sexual orientation is related to her antecedent of cryptorchidism, as she reflected on her related negative experiences, she concluded that her gender identity and sexual orientation trajectories, as well as her life in general, would have been completely different if there were no clinical interventions in her early development. Discussion and conclusion. The present case could have been benefited from not receiving early treatment for her cryptorchidism. There is an urgent need for the development of standardized protocols or algorithms for physical and mental health care professionals, which focus on supportive guidance rather than adjustment to parental and medical expectations.
\end{abstract}

Keywords: Gender identity, transgender, gender, psychological intervention, case study.

\section{RESUMEN}

Este artículo presenta la historia clínica y de vida de una mujer transexual con criptorquidia al nacer. Nuestro objetivo es presentar un estudio de caso en que la identidad transgénero y la criptorquidia, una condición testicular común en niños e identidades trans, podrían cumplir un papel en los procesos de formación de identidad de género. La interacción entre la identidad de género y la orientación sexual también se presenta como entrevistas semiestructuradas destinadas a recopilar datos sobre intervenciones clínicas tempranas según lo informado por la persona. Abogamos por un algoritmo psicológico que abarque la comunicación interprofesional específicamente diseñada para las personas con diferencias de sexo/género, centrándose en la orientación de apoyo en lugar de ajustarse a las expectativas médicas y de los padres.

Palabras clave: Identidad de género, transgénero, género, intervención psicológica, estudio de caso. 


\section{INTRODUCTION}

The attainment of gender identity is a complex process that, ultimately, guarantees the psychological well-being of the individual beyond the realm of personal identity and sexuality. This intricate process includes physical, psychological, social, emotional, and, for some people, spiritual domains. Therefore, biological and psychological aspects of human gender and sexuality are deeply intertwined as reflected, but not limited to, behaviour, desire, affects, roles, relationships, values, and culture (Lamas, 2012).

Clinical interventions to address sex and gender variance often aim to conform individuals to cultural values on the acceptable boundaries between the binary models including only two different categories: male or female. Thus, transgender people are defined as those whose identity and/or gender expression does not correspond to the social norms and expectations associated with their sex at birth (Pan American Health Organization, 2011). It also encompasses male and female impersonators, especially in the context of artistic performance; individuals who define themselves as bi-gender, gender queer, and gender variant, as well as anyone expressing gender characteristics that do not correspond with those traditionally associated with the sex assigned at birth (Bockting, Benner, \& Coleman, 2009).

Although many transgender people are clear about their tastes, attractions, activities, and gender preferences from childhood, they often spend years trying to understand their own identity and may decide to keep it secret, usually to avoid adverse reactions from others (Robles et al., 2016). Some transgender people undergo hormonal and/or surgical treatment to change their bodies, while others do not wish to alter their bodies. Others may consider a legal change of sex as the ultimate evidence of their identity. The process that entails varied gender expressions can be as unique as the psychological needs or support that everyone may need throughout the lifespan.

It is during puberty, which is characterized by the overt development of secondary sexual characteristics, that transgender people often report discomfort with their bodies. Although this displeasure may disappear over time, it is a tenet in psychology and psychiatry that psychological and medical treatment is warranted (Hyderi et al., 2016). But given that this is a sub-specialty within each clinical field, it is not trivial for transgender persons to find qualified professionals while seeking psychological and medical support. When this need is not met, mental and physical health issues can lead to life-threatening situations intimately related to gender identity (United Nations Programme on HIV/ AIDS, 2014).

According to current nosological classifications: ICD10 of the World Health Organisation, and DSM-5 of the American Psychiatric Association (World Health Organization, 1992; American Psychiatric Association, 2013), transgenderism has been used to describe the experiences of all those located somewhere along the poles of male and female in the spectrum of sex and gender expressions. In ICD-10, for example, this condition is described as the "desire to live and be accepted as a member of the opposite sex, usually accompanied by feelings of discomfort or disagreement with one's own anatomical sex and the wish to undergo surgical or hormonal treatment to make the body as consistent as possible with the preferred sex" (World Health Organization, 1992, pp. 168).

On the other hand, cryptorchidism is defined as the absence of one or both testicles in the scrotal sac due to an undescended or maldescended testis (Brinkmann, Schuetzmann \& Richter-Appelt, 2007; American Urological Association, 2014). This condition can be expressed among $46, \mathrm{XY}$ persons, and it does not necessarily reflect an intersex diagnosis. Its prevalence ranges from $0.7 \%$ to $8 \%$ in newborns and up to 30\% among premature babies (Comité Nacional de Endocrinología, 2001; Garnelo \& Caamaño, 2005; Secretaría de Salud, 2014). Testis descent can occur at three months of age, although this is less common ( $2 \%$ of reported cases) (Berkowitz et al., 1993).

Current medical treatment of cryptorchidism involves identifying the existence of the gonad and giving it a suitable location to reduce the risk of infertility, inguinal hernia, cancer, and testicular torsion (Ferguson \& Agoulnik, 2013). Additionally, untreated cryptorchidism might be related also with long-term effects of hormonal therapy, recurring medical examinations, and manipulations, as well as with psychosocial negative outcomes (including anxiety, depression, social, and scholastic maladjustment, etc.) given that testicles may be symbols of strength, virility, fertility, aggressiveness, and sexuality (Sumfest \& Kim, 2018). Thus, many clinicians believe that it should be performed as early as possible, when irreversible changes occur in testicular morphology (Nagar \& Haddad, 1997; Docimo, Silver, \& Cromie, 2000; Mayo Clinic, 2017); and current guidelines recommend early interventions in order to prevent cancer and infertility (Secretaría de Salud, 2014; American Academy of Pediatrics, 2000), and to reduce the anxiety of the family in defining the sex with which the baby should be raised.

In contrast, there is also evidence that successful scrotal repositioning of the testis does not prevent the potential long-term issues of infertility and testis cancer (Comité Nacional de Endocrinología, 2009; American Urological Association, 2014), and according to Sumfest et al. (2018) there has been little research about the rest of the possible negative consequences, and even less information about issues of psychosexual identity derived from cryptorchidism's treatment or absence of treatment (Conolly, 1959; Cytryn, Cytryn, \& Rieger, 1967; Masi et al., 1999; Galifer, Kalfa, \& Guibal, 2004). Thus, it has also been suggested that clinical intervention should wait for persons to develop 
their gender identity and be able to participate in the decision-making process. This is more so taking into account that gender identity is defined very early in childhood, approximately between the third and fifth year of age (Robles et al., 2016).

As can be seen, the decision of clinical interventions in the case of children with this condition becomes a dilemma between the child's rights to determine their own sexual characteristics according to her/his gender identity (in the very near future) against the possible problems of living as a child with an indeterminate gender. In the case of the treatment of cryptorchidism, the decision of an early intervention is more unanimous and gender identity matters are considered more as a possible consequence of not treating the cryptorchidism than as a consequence of the its treatment.

\section{Cryptorchidism, transgenderism, and sexual orientation}

The variation between sex assigned at birth and the gender identity adopted by a person is not directly related to sexual orientation. Sexual orientation is defined, according to the Pan American Health Organization (2011, p. 13) as: the specific organization of eroticism and the emotional bond of an individual in relation to the gender of the partner involved in sexual activity, and can be expressed as behaviours, thoughts, or sexual fantasies, or a combination of these elements.

In other words, a transgender person may have any sexual orientation, and may or may not present a biological intersex condition. In turn, people with an intersex condition may regard themselves as transgender (Cabral, 2009), although most are not (Reisner et al., 2016). It is not clear how sexual orientation relates to intersex diagnosis, sex assignment at birth, and the medical treatment to which they were subjected to (Reiner \& Gearhart, 2004). Therefore, although there may be cases in which intersexuality and transgenderism may coexist with non-normative heterosexual thoughts, fantasies, or behaviours, none of these is the sine qua non of the other. In fact, there is a wide range of possible combinations in relation to sex at birth, gender identity, and sexual orientation.

Specific medical and psychological treatment needs may also vary depending on these combinations. For instance, major surgical interventions in people with intersex conditions (as genitoplacia and gonadectomy) are different from those for a transgender person (Reisner et al., 2016). Nevertheless, they may share physical and psychological needs that primarily stem from medical treatments as well as from stigma and social rejection (Subhrajit, 2014), and mental health care professionals must be prepared to assist these sexual minority populations at any time during their lifespan (Leidolf, Curran, \& Scout Bradford, 2008; Mayer et al., 2008).
In order to promote interventions that focus on the perceived needs of those directly involved rather than to parental and medical expectations, the aim of the present case study is to describe the clinical and life histories of a transsexual woman with a history of cryptorchidism at birth and examine the interplay between this relative common testicular problem at birth, and the gender identity and sexual orientation formation processes from her own perspective.

\section{METHODS}

This is a qualitative study based on a case referred to an indepth interview during a larger study: "Towards the Categories of Gender Discordance in ICD-11," approved by the Ethics Committees of Research of the Instituto Nacional de Psiquiatría Ramón de la Fuente Muñíz. The interviews were conducted by the author, a female researcher with a master's degree, who previously received training from a psychiatrist expert in qualitative methodology. The interviewer at the time of the study was studying a doctorate whose thesis project was about aspects of identity development in childhood. The person interviewed participated in a project on Categories of Gender Discordance in ICD-11, and at the end of her survey she was asked to participate in a project that delved into the process of transgender identity in childhood and was referred to participate in a semistructured interview. The interview was conducted at a care centre specialized in transgender person's health attention in Mexico City, Mexico, at a private doctor's office, and after explaining the purpose of the study and obtaining written informed consent to participate.

The participant was the only person to refer a medical history on her genitals. For this reason, she was asked to attend again to be interviewed and repeat the process to inquire about the possible impact of the medical condition on the development of her identity, and thus repeat the process. Duration of the interviews was approximately three hours; interviews were audio recorded and transcribed for a content analyses. The content of the interviews was analysed by three researchers.

\section{RESULTS}

Due to the large amount of information obtained from the interviews, this article will present only the most relevant information. Data are organized in two dimensions: Transgender identity and Cryptorchidism with two categories and fourteen sub-categories (Table 1).

\section{Case description}

Gia was 43 years-old at the time of the interview and was married and childless. She was assigned to the male sex and 
Table 1

Dimensions and categories

\begin{tabular}{|c|c|c|c|}
\hline \multicolumn{2}{|c|}{ Dimension: transgender identity } & \multicolumn{2}{|c|}{ Dimension: cryptorchidism } \\
\hline Categories & Subcategories & Categories & Subcategories \\
\hline \multirow[t]{4}{*}{ Gender identity } & $\begin{array}{l}\text { Process of developing gender } \\
\text { identity }\end{array}$ & Cryptorchidism & Sex at birth \\
\hline & $\begin{array}{l}\text { Consequences related to gen- } \\
\text { der identity }\end{array}$ & & $\begin{array}{l}\text { Medical intervention for cryptor- } \\
\text { chidism }\end{array}$ \\
\hline & Sexual and emotional aspects & $\begin{array}{l}\text { Hypothetical } \\
\text { situation }\end{array}$ & $\begin{array}{l}\text { Possible physical consequences } \\
\text { of not having been operated on }\end{array}$ \\
\hline & $\begin{array}{l}\text { Secondary sexual character- } \\
\text { istics }\end{array}$ & & $\begin{array}{l}\text { Potential impact of orchiopexy } \\
\text { on gender identity and self-per- } \\
\text { ception }\end{array}$ \\
\hline Turning point & Reaffirmation of self-identity & & $\begin{array}{l}\text { Potential emotional conse- } \\
\text { quences of not receiving treat- } \\
\text { ment }\end{array}$ \\
\hline \multirow[t]{2}{*}{ Health care } & $\begin{array}{l}\text { Seeking care for gender iden- } \\
\text { tity }\end{array}$ & Suggestions & $\begin{array}{l}\text { Recommendation regarding } \\
\text { treatment of cryptorchidism }\end{array}$ \\
\hline & $\begin{array}{l}\text { Medical intervention for gen- } \\
\text { der identity }\end{array}$ & & \\
\hline Suggestions & $\begin{array}{l}\text { Recommendation regarding } \\
\text { gender identity }\end{array}$ & & \\
\hline
\end{tabular}

Table 2

Quotes from gender identity dimension

\begin{tabular}{|c|c|}
\hline Categories & Text \\
\hline $\begin{array}{l}\text { Process of developing } \\
\text { her gender identity }\end{array}$ & $\begin{array}{l}\text { 'At the age of } 4 \text {, I identified more with women than men, I got along better with women, sang with them, } \\
\text { ate with them, and secretly dressed like them and wore make-up. Music, cars and football, are things } \\
\text { I could do without, I was always bad at sport and focused on schoolwork'. }\end{array}$ \\
\hline $\begin{array}{l}\text { Consequences related } \\
\text { to gender identity }\end{array}$ & $\begin{array}{l}\text { 'People thought I was strange, talked behind my back and would not let me go on with my life. I was } \\
\text { bullied at school, I knew something was wrong with me, I did not have a pleasant life, I went to live } \\
\text { with an aunt and when I couldn't find myself what was wrong with me, I tried to kill myself: I did not } \\
\text { feel right as a boy, people laughed and teased me, I was deeply depressed. I did not have a nice } \\
\text { life, I did not identify with my family, I just concentrated on studying and tried to do the things I liked, } \\
\text { because I was pretty good at school, but I did not want to go home, I had problems at home with my } \\
\text { dad, problems about what I wore, the way I dressed, the way I combed my hair. I went to live with an } \\
\text { aunt at } 14 \text { and when I couldn't find myself or, someone to tell me what was wrong with me, I tried to } \\
\text { kill myself, I attempted suicide'. }\end{array}$ \\
\hline
\end{tabular}

Sexual and emotional 'I was a totally asexual person, I was a really introverted person, I was a person who would not let aspects anyone get into my world, I was completely antisocial'.

Secondary sexual characteristics

'During puberty, all the physical changes affect you, they get to you and I also started getting depressed and felt really lonely. It started off as depression, then it was like trying to get the most out of my body, if that was what my life was going to be like. My voice had broken and there were many other things in the process of masculinisation that I couldn't reverse'.

Reaffirmation of $\quad$ 'Once I had a problem with my colon so I had an operation. I didn't want to live and I told my family: if self-identity I'm going to live, it will be on one condition; I do not want to live the way I did before, I want to live the way I want, period. The only purpose is to be happy, I do not want to look back, that's when my life began again; everything was different'.

Seeking care for gender identity

'When I was 11, they took me to a psychologist and a psychiatrist, because I looked bad, because I had identity problems, and lots of other things. They said I had a gender disparity, but I can't remember anything else. That did not help because what they told my mom to make me play football and spend more time with other boys'. 'When I was 27, 28 years I went to a group of transvestites for two sessions but I got bored and never went back. I was looking for someone who felt like me at that time, and not only that, I wanted a space where I could express myself and my feelings and everything'.

Medical intervention for gender identity
'At 37, I started going to psychotherapy and getting hormone treatment to be who I really am, I identify myself as transgender woman and that means respect, dignity, it means knowing who you are, I have grown personally, with my family, as a couple, there are no more problems about gender, just being who you want to be'. 
Table 3

Quotes from cryptorchidism dimension

\begin{tabular}{|c|c|}
\hline Categories & Text \\
\hline Sex at birth & $\begin{array}{l}\text { 'The sex I was given at birth was ambiguous genitalia. It was, therefore, decided that this was a strictly } \\
\text { medical issue, and the decision was taken to bring my testicles down, as a result of which I had a male } \\
\text { gender assigned to me'. }\end{array}$ \\
\hline $\begin{array}{l}\text { Medical intervention } \\
\text { for cryptorchidism }\end{array}$ & $\begin{array}{l}\text { 'When I was } 14, \text { I was talking to my mom one day. She took out my birth certificate and the medical } \\
\text { report and that was when she told me about my birth condition, I began to feel many things like why } \\
\text { didn't they let me go on being a girl? Why they did not do anything? Why? I was really upset'. }\end{array}$ \\
\hline $\begin{array}{l}\text { Possible physical } \\
\text { consequences of not } \\
\text { having been operated } \\
\text { on }\end{array}$ & $\begin{array}{l}\text { 'The truth is that whole way of perceiving masculinity would have been totally different. If my testicles } \\
\text { hadn't dropped, I would have felt different and not chosen to do sports. What did they do that made } \\
\text { my bones and my body grow? It's not that I would not have used them. It was wonderful to do it and I } \\
\text { would do it again but I think with a condition of cryptorchidism, I would not have done it. That's a fact, } \\
\text { I would have been at a different level, at an intermediate level and in that intermediate plane maybe } \\
\text { lots of things would have happened, or maybe I would just have been a person with a fluid gender'. }\end{array}$ \\
\hline $\begin{array}{l}\text { Potential impact of } \\
\text { orchiopexy on gender } \\
\text { identity and self-per- } \\
\text { ception }\end{array}$ & $\begin{array}{l}\text { 'I feel that things would not have been the same, I would not have expressed myself that way, I would } \\
\text { have been } 100 \% \text { female. You're the first person who has ever asked me this, I had not thought about it } \\
\text { until now but it is a fact, I feel that it would have been different, maybe I would not have been a totally } \\
\text { introverted person because for me it was a limitation on what I wanted to be and look like. I used to } \\
\text { look at my sister; I wanted to have everything they did for my sister. Not having visible testicles would } \\
\text { have been } 100 \% \text { different'. }\end{array}$ \\
\hline $\begin{array}{l}\text { Potential emotional } \\
\text { consequences of not } \\
\text { receiving treatment }\end{array}$ & $\begin{array}{l}\text { 'Emotionally, my whole life, I was a very hard person. At first, I was very introverted, I felt that things } \\
\text { were different for me in life; I felt things were a bit complicated. If you like, because I felt rejected by } \\
\text { my family, I felt people's disgust; I felt many things, so I would have been on a different level. Maybe if } \\
\text { I had felt that way from the beginning, I would not have been a totally introverted person. If I had been } \\
\text { a total extrovert, I would have been another kind of person, everything would have happened before, } \\
\text { I wouldn't have had to leave my family circle'. }\end{array}$ \\
\hline
\end{tabular}

was diagnosed with cryptorchidism. She identified herself as a transgender woman and as lesbian. At the time of the interview, she had been undergoing hormone therapy for four years and had no plans for any sexual reaffirmation surgery.

\section{Dimensions gender identity and cryptorchidism}

These dimensions describe events that the participant was reporting as they occurred in time. The dimension on gender identity (Table 2 ) begins with the age at which the participant recognizes the beginning of the process that leads to the appearance of secondary sexual characteristics and their negative impact. Highlight the consequences related to the reactions of other people and not of the gender identity itself in childhood and adolescence, and a turning point in adulthood when she finally negotiates with her family and determines that she will live as she always wished or prefers to die. It also describes a little about her experiences in the search for help. The dimension of cryptorchidism (Table 3) provides information on when and how the participant obtains information about her genitals condition at birth and the medical procedures to which she was subjected. And describe in and hypothetically way, how it would have benefited from not having been treated medically, from bodily changes, a better relationship with the family, an earlier and smoother gender identity transition, and less emotional conflicts.

\section{Categories recommendations from life experience}

The categories recommendations from life experience (Table 4) provide information about the need to provide information and education on the subject of gender identity from schools, family counseling, medical personnel, and society in general. Regarding cryptorchidism, the participant clearly understands that it is a dilemma and that there is no causal relationship between cryptorchidism and a transgender identity and the importance of considering that the person can decide on her diagnosis and treatment.

\section{DISCUSSION AND CONCLUSIONS}

Regarding gender identity, as happens with most transsexual people (Bradley \& Zucker, 1997), Gia began to become aware of her gender discordance in childhood. She had clearly different tastes and preferences from what was culturally expected for the sex assigned at birth right after the intervention due to her intersex condition. In many cases, this is related to the presence of family, social, and emotional problems resulting from stigma and discriminatory attitudes. In keeping with the findings in the scientific literature (Steensma et al., 2011), adolescence was one of the most difficult life stages to cope with for Gia; social maladjustments were exacerbated by gender discordance due to the 
Table 4

Quotes of categories: recommendations from life experience

\begin{tabular}{ll}
\hline Categories & \multicolumn{1}{c}{ Text } \\
$\begin{array}{l}\text { What would you } \\
\text { recommend regarding } \\
\text { gender identity? }\end{array}$ & $\begin{array}{l}\text { 'With regard to gender, culture and education, a children's book with transsexual topics to teach fu- } \\
\text { education, and understanding at the family, student and life level. That is all they need to get on in } \\
\text { life. Everything else, medical, hormonal, diagnosis, psychological treatment, is just icing on the cake; } \\
\text { but having understood from the time they are at school would go a long way to making things better'. }\end{array}$ \\
$\begin{array}{l}\text { What would you } \\
\text { recommend regarding } \\
\text { treatment of cryptor- } \\
\text { chidism? }\end{array}$ & $\begin{array}{l}\text { 'It's a gamble and I don't blame the doctors. Who knows if they were wrong or not, how were they to } \\
\text { able to decide later, not have to register, not in the legal field. If they had let me be, I think I would have } \\
\text { had the choice of deciding later, I would have seen how I felt, if I didn't feel comfortable, if there was } \\
\text { a problem, although there could have been other secondary factors as a result of that, I do not know } \\
\text { but I think the best thing to do would be to change the protocol and immediately register the baby as a } \\
\text { boy or a girl, even if it has ambiguous genitalia, immediately when it is born, I think that is better, rather } \\
\text { than having to wait for a diagnosis'. }\end{array}$ \\
\hline
\end{tabular}

emergence of unwanted secondary sexual characteristics in relation to her gender identity.

Gia consulted health professionals who failed to help her; it was not until she was 37 years-old that she was able to begin her body reconfiguration to adjust her self-representation as a transgender woman. The consequences of inefficient or even damaging interventions caused by medical and psychological treatments shows the urgent need for the development of standardized protocols or algorithms for health care professionals.

\section{Cryptorchidism and transgender identity}

Although it is not possible to conclude that Gia's gender identity is related to her antecedent of cryptorchidism, as she reflected on her medical and life histories, she could only imagine what would have been different for her if there were no clinical interventions in her early development. She concluded that her gender trajectories and her life in general would have been completely different from what she came to feel and to express as a female.

In this sense, the case illustrates that, despite the good intentions of her parents and the medical team, clinical management can violate bodily autonomy and human dignity (Kessler, 1997). The central argument justifying current clinical protocols assumes that the same biological processes that determine and differentiate genital anatomy also play a role in the processes that leads to gender identity formation. The paradoxical term 'embryology of gender' has been proposed to highlight this faulty logic that lacks scientific evidence (Jorge, 2010). Thus, in some clinical practice guidelines for the diagnosis and treatment of cryptorchidism, which involve the participation of paediatricians, urologists, surgeons, endocrinologists and other medical professionals (Hughes et al., 2006), no mention is made of mental health staff or of the parents' involvement during the decision-making process (Jorge \& Agramonte, 2013).
Given that the attainment of gender identity is a complex process that guarantees the well-being of the individual beyond the realm of sexuality, it is of critical importance that psychological support is in place to accompany people through clinical interventions. The notion that transgenderism, intersexuality, and genital abnormalities are medical and social emergencies is outdated as we have come to appreciate a spectrum of valid genital anatomies and gender identities that express themselves in thoughts, fantasies, desires, and behaviours that are intrinsic to the human experience as sexual beings. Therefore, we advocate for a psychological algorithm that embraces inter-professional communication specifically designed for people with sex/ gender variance focusing on supportive guidance rather than adjustment to parental and medical expectations.

Many urologists and paediatricians might be convinced of the emotional impact of cryptorchidism in children, resting importance to possible negative consequences of its early treatment. However, as it is clearly seen in the case presented here, some people could benefit from not receiving any treatment, and the possible complications of not receiving treatment remain unknown.

\section{Disclosure statement}

No potential conflict of interest was reported by the authors.

\section{Funding}

The Consejo Nacional de Ciencia y Tecnología (CONACyT) through doctoral scholarship (T. R.).

\section{REFERENCES}

American Academy of Pediatrics. (2000). Committee on Genetics, Section on Endocrinology, Section on Urology. 2000. Evaluation of the newborn with developmental anomalies of the external genitalia. Pediatrics, 106(1), 138-142.

American Psychiatric Association. (2013). Diagnostic and statistical manual of mental disorders (5th ed.). Washington, DC. 
American Urological Association. (2014). Evaluation and treatment of cryptorchidism: AUA guideline. American Urological Association.

Berkowitz, G., Lapinski, R., Dolgin, S., Gazella, J., Bodian, C., \& Holzman, I. (1993). Prevalence and natural history of cryptorchidism. Pediatrics, 92(1):4449. PMID: 8100060

Bockting, W. O., Benner, A., \& Coleman, E. (2009). Gay and bisexual identity development among female-to-male transsexuals in North America: Emergence of a transgender sexuality. Archives of Sexual Behavior, 38(5), 688-701. doi: 10.1007/s10508-009-9489-3

Bradley, S. \& Zucker, K. (1997). Gender Identity Disorder: A review of the past 10 years. Journal of the American Academy of Child \& Adolescent Psychiatry, 36(7), 872-880. doi: 10.1097/00004583-199707000-00008

Brinkmann, L., Schuetzmann, K., \& Richter-Appelt, H. (2007). Gender assignment and medical history of individuals with different forms of intersexuality: evaluation of medical records and the patients' perspective. The Journal of Sexual Medicine, 4, 964-980. doi: 10.1111/j.1743-6109.2007.00524.x

Cabral, M. (2009). Interdicciones: Escrituras de la intersexualidad en castellano. M. Cabral, Editor. Argentina: Annarés Editorial. Retrieved from: www.mulabi.org/ Interdicciones2.pdf

Comité Nacional de Endocrinología. (2001). Recomendaciones para el diagnóstico y tratamiento de la criptorquidia. Archivos Argentinos de Pediatría, 99(4), 372374.

Comité Nacional de Endocrinología. (2009). Tendencias actuales en el tratamiento y seguimiento de la criptorquidia. Archivos Argentinos de Pediatría, 107(2), 176-180.

Connolly, N. K. (1959). Maldescent of the testis. American Surgery, 25, 405-420.

Cytryn, L., Cytryn, E., \& Rieger, R. (1967). Psychological Implications of Cryptorchism. Journal of American Academy of Child and Adolescent Psychiatry, 6(1), 131-165. doi.org/10.1016/S0002-7138(09)61294-2

Docimo, S., Silver, R., \& Cromie, W. (2000). The Undescended Testicle: Diagnosis and Management. American Family Physician, 62(9), 2037-2044.

Ferguson, L. \& Agoulnik, A. (2013). Testicular Cancer and Cryptorchidism. Frontiers in Endocrinology (Lausanne), 4(32), 1-9. doi: 10.3389/fendo.2013.00032

Galifer, R. B., Kalfa, N., \& Guibal, M. P. (2004). What a hidden testicule can hide? or the clinical traps of cryptorchidism. Archives de Pédiatrie, 11(4), 350-359. doi: 10.1016/j.arcped.2003.11.015

Garnelo, L. \& Caamaño B. (2005). Criptorquidia. Guías clínicas, 5(26), 1-3.

Hughes, I., Houk, C., Ahmed, S., Lee, P., Lawson Wilkins Pediatric Endocrine Society (LWPES)/European Society for Pediatric Endocrinology (ESPE) Consensus Group. (2006). Consensus statement on management of intersex disorders. Journal of Pediatric Urology, 2(3), 148-162. doi: 10.1016/j.jpurol.2006.03.004

Hyderi, A., Angel, J., Madison, M., Perry, L. A., \& Hagshenas, L. (2016). Transgender patients: Providing sensitive care. The Journal of Family Practice, 65(7), 45061.

Jorge, J. C. (2010). La embriología del género y modelos moleculares emergentes para explicar la diferenciación sexual. Sexología, 15(2), 37-49. English version: Jorge, J. C. 2010. The embryology of gender. Journal of LGBT Youth, 7, 310319

Jorge, J. C. \& Agramonte, A. (2013). Standards of care for congenital adrenal hyperplasia: a call for change in the Caribbean region. Sexuality Research and Social Policy, 10(3), 233-241. doi: 10.1007/s13178-013-0110-0

Kessler, S. (1997). Meanings of gender variability. Chrysalis: The Journal of Transgressive Gender Identities, 2(5), 33-38.
Lamas, M. (2012). Transexualidad: identidad y cultura. México: Universidad Nacional Autónoma de México. Retrieved from: http://biblio.unam.mx:8070/ index.php/novedades/adquisiciones-tesis/109-t9

Leidolf, E. M., Curran, M., \& Scout-Bradford J. (2008). Intersex mental health and social support options in pediatric endocrinology training programs. Journal of Homosexuality, 54(3), 233-42. doi: 10.1080/00918360801982074

Masi, G., Millepiedi, S., Brovedani, P., Favilla, L., \& Mucci, M. (1999). Psychopathological aspects of cryptorchidism in children and adolescents. Child Psychiatry and Human Development, 30(2), 75-85. doi: 10.1023/A:1021946201023

Mayer, K., Bradford, J., Makadon, H., Stall, R., Goldhammer, H., \& Landers, S. (2008). Sexual and gender minority health: what we know and what needs to be done. American Journal of Public Health, 98(6), 989-995. doi: 10.2105/ AJPH.2007.127811

Mayo Clinic. (2017). Undescended testicle. Treatment. Retrieved from: https://www. mayoclinic.org/diseases-conditions/undescended-testicle/diagnosis-treatment/ drc-20352000

Nagar, H. \& Haddad, R. (1997). Impact of early orchidopexy on testicular growth. British Journal of Urology, 80(2), 334-335. doi: 10.1046/j.1464-410X.1997. t01-1-00301.x

Pan American Health Organization. (2011). The Right of Young People to Health and Gender Identities: Findings, Trends, and Targets for Public Health Action. Washington: Pan American Health Organization.

Reiner, W. \& Gearhart, J. (2004). Discordant Sexual Identity in Some Genetic Males with Cloacal Exstrophy Assigned to Female Sex at Birth. New England Journal of Medicine, 350(4), 333-341. doi: 10.1056/NEJMoa022236

Reisner, S., Poteat, T., Keatley, J. A., Cabral, M., Mothopeng, T., Dunham, E., ... Baral, S. (2016). Global health burden and needs of transgender populations: a review. Lancet, 388(10042), 412-436. doi: 10.1016/S0140-6736(16)00684-X

Robles, R., Fresán, A., Vega-Ramírez, H., Cruz-Islas, J., Rodríguez-Pérez, V., Domínguez-Martínez, T., \& Reed, G. M. (2016). Removing transgender identity from the classification of mental disorders: a Mexican field study for ICD-11. Lancet Psychiatry, 3(9), 850-859. doi: 10.1016/S2215-0366(16)30165-1

Secretaría de Salud. (2014). Diagnóstico y tratamiento del testículo no descendido. México: Secretaría de Salud.

Steensma, T. D., Biemond, R., de Boer, F., \& Cohen-Kettenis, P. T. (2011). Desisting and persisting gender dysphoria after childhood: a qualitative follow-up study. Clinical Child Psychology and Psychiatry, 16(4), 499-516. doi: 10.1177/1359104510378303

Subhrajit, C. (2014). Problems Faced by LGBT People in the Mainstream Society: Some Recommendations. International Journal of Interdisciplinary and Multidisciplinary Studies, 1(5), 317-331.

Sumfest, J. \& Kim, E. D. (2018). Cryptorchidism Treatment and Management. Drug and Diseases, Urology. Retrieved from: https://emedicine.medscape.com/ article/438378-treatment

United Nations Programme on HIV/AIDS. (2014). The gap report 2014. Transgender people. Geneva: United Nations. Retrieved from: http://www.unaids.org/sites/ default/files/media asset/08 Transgenderpeople.pdf

World Health Organization. (1992). The ICD-10 classification of mental and behavioral disorders: clinical descriptions and diagnostic guidelines. Geneva: World Health Organization. 